\title{
The influence of calcium and magnesium in drinking water and diet on cardiovascular risk factors in individuals living in hard and soft water areas with differences in cardiovascular mortality Christina Nerbrand*1, Lars Agréus ${ }^{2}$, Ragnhild Arvidsson Lenner ${ }^{3}$, Per Nyberg ${ }^{4}$ and Kurt Svärdsudd ${ }^{5}$
}

\begin{abstract}
Address: ${ }^{1}$ Primary Care R\&D, Department of Medicine, University of Lund, SE-221 85 Lund, Sweden, ${ }^{2}$ Family Medicine Stockholm, Karolinska Institutet, Stockholm, SE-141 57 Huddinge, Sweden, ${ }^{3}$ Department of Clinical Nutrition, Sahlgrenska Academy at Göteborgs University, SE-413 45 Göteborg, Sweden, ${ }^{4}$ Primary Care R\&D, Department of Caring Sciences, University of Lund, SE-221 85 Lund, Sweden and ${ }^{5}$ Department of Public Health and Caring Science, Section of Family Medicine, University of Uppsala, SE-751 85 Uppsala, Sweden
\end{abstract}

Email: Christina Nerbrand* - christina.nerbrand@skane.se; Lars Agréus - lars.agreus@klinvet.ki.se; Ragnhild Arvidsson Lenner - ragnhild.lenner@nutrition.gu.se; Per Nyberg - per.nyberg@skane.se; Kurt Svärdsudd - kurt.svardsudd@pubcare.uu.se

* Corresponding author

Published: 18 June 2003

BMC Public Health 2003, 3:21
Received: II December 2002

Accepted: 18 June 2003

This article is available from: http://www.biomedcentral.com/I47I-2458/3/2I

(c) 2003 Nerbrand et al; licensee BioMed Central Ltd. This is an Open Access article: verbatim copying and redistribution of this article are permitted in all media for any purpose, provided this notice is preserved along with the article's original URL.

\begin{abstract}
Background: The role of water hardness as a risk factor for cardiovascular disease has been widely investigated and evaluated as regards regional differences in cardiovascular disease. This study was performed to evaluate the relation between calcium and magnesium in drinking water and diet and risk factors for cardiovascular disease in individuals living in hard and soft water areas with considerable differences in cardiovascular mortality.
\end{abstract}

Methods: A random sample of 207 individuals living in two municipalities characterised by differences in cardiovascular mortality and water hardness was invited for an examination including a questionnaire about health, social and living conditions and diet. Intake of magnesium and calcium was calculated from the diet questionnaire with special consideration to the use of local water. Household water samples were delivered by each individual and were analysed for magnesium and calcium.

Results: In the total sample, there were positive correlations between the calcium content in household water and systolic blood pressure (SBP) and negative correlations with s-cholesterol and s-LDLcholesterol. No correlation was seen with magnesium content in household water to any of the risk factors.

Calcium content in diet showed no correlation to cardiovascular risk factors. Magnesium in diet was positively correlated to diastolic blood pressure (DBP). In regression analyses controlled for age and sex $18.5 \%$ of the variation in SBP was explained by the variation in BMI, HbAlc and calcium content in water. Some $27.9 \%$ of the variation in s-cholesterol could be explained by the variation in s-triglycerides (TG), and calcium content in water.

Conclusions: This study of individuals living in soft and hard water areas showed significant correlations between the content of calcium in water and major cardiovascular risk factors. This was not found for magnesium in water or calcium or magnesium in diet. Regression analyses indicated that calcium content in water could be a factor in the complexity of relationships and importance of cardiovascular risk factors. From these results it is not possible to conclude any definite causal relation and further research is needed. 


\section{Background}

In a study of regional differences in mortality in cardiovascular diseases in 76 municipalities in mid-Sweden a considerable gradient was found between the western areas with high mortality and soft water and the eastern areas with low mortality and hard water. The hardness of water defined as the sum of the content of calcium and magnesium, was shown to be of considerable influence on the differences in mortality compared to major risk factors [1].

The incidence of coronary heart disease varies widely in different geographical regions over the world and serious epidemiological studies have been carried out to identify variables that could explain this fact. The role of water hardness has been widely investigated and evaluated for many years in several studies where regional differences in cardiovascular disease have been discussed [1-12].

Extensive reviews indicate the difficulties in interpreting the results of many studies and also point out the need for further studies including intervention $[13,14]$. Previous studies have found positive correlations between water and dietary magnesium and calcium and blood pressure $[13,15-17]$. In Finland and South Africa it was found that the incidence of death ascribed to ischaemic heart disease is inversely correlated with the concentration of magnesium in drinking water [6,7]. A post mortem study has demonstrated significantly reduced intramyocardial and coronary arterial wall magnesium levels in road accident victims who lived in areas where water supplies have low magnesium content $[18,19]$. However, other studies could not confirm these findings [20,21]. In a Swedish study the skeletal muscle magnesium levels were significantly higher in persons living in an area with higher water magnesium [22]. The concentration of magnesium in striated muscle has been used as a marker to evaluate the ion content in the soft tissue and therefore we conducted muscle biopsy in a sub-group of individuals.

Mineral-rich water could provide an important supplementary contribution to total calcium and magnesium intake according to results from a French study [23].
In a Swedish case control study magnesium and calcium in drinking water were associated with lower mortality from acute myocardial infarction in women but not with the total incidence. In these studies there was no recording of the diet. The presence of risk factors was ascertained by interviews of surviving cases and controls, and no analyses of lipids were made $[9,10]$.

There are however also studies where the results are not as conclusive, in a case control study of men in Finland with a 10-year follow-up there were no significant differences in concentrations of serum calcium and serum magnesium between cases who died from cardiovascular diseases and controls [11]. In a study of magnesium in drinking water supplies and mortality from acute myocardial infarction in north-west England, there was likewise evidence of an association between magnesium and cardiovascular mortality [12]. The aim of the present study of individuals living in two of the 76 municipalities on the extreme in our previous study was to show the influence of magnesium and calcium intake in water and diet on major cardiovascular risk factors; s-cholesterol, s-TG, sLDL, SBP and DBP.

The water from the major water supplies in the municipality in the east had a higher degree of hardness, $66 \mathrm{mg} / \mathrm{ml}$ of calcium and $4.1 \mathrm{mg} / \mathrm{ml}$ of magnesium, than in the municipality in the west with $8.8 \mathrm{mg} / \mathrm{ml}$ and $0.74 \mathrm{mg} / \mathrm{ml}$ respectively [24]. Age-standardised rates for total mortality, mortality from cardiovascular disease and ischaemic heart disease (IHD) for men and women aged 45-64 years in the two municipalities 1989-98 are shown in Table 1 [25]. All differences were significant $\mathrm{p}<0.0001$ with higher mortality rates in the western municipality.

\section{Methods}

Two random samples of 120 individuals aged 40-59 years were drawn from the official register of the total population in each of two municipalities. One of the municipalities, Tocksfors, in the western part of Sweden, was characterised by soft water and high cardiovascular mortality, and the other, Osthammar, situated in the eastern part of Sweden, by hard water and low mortality. Both municipalities are mainly rural areas with a population of the same size.

Table I: Standardised mortality cases per 1000 inhabitants, population and risk ratio (SMR) for inhabitants aged 45-64 in the two municipalities in the west and east part of Sweden 1989-1998.

\begin{tabular}{lllllll}
\hline & West Men & East Men & SMR Men & West Women & East Women & SMR Women \\
\hline Population & 1192 & 2717 & & 1116 & 2384 & \\
Total mortality/1000 inh & 67.95 & 55.58 & 1.22 & 54.66 & 36.49 & 1.50 \\
Mortality from cardiovascular disease//000 inh & 31.04 & 19.87 & 1.56 & 10.75 & 6.29 & 1.71 \\
Mortality from IHD/I000 inh & 20.97 & 10.31 & 2.03 & 5.38 & 2.10 & 2.56 \\
\hline
\end{tabular}

All differences are significant $p<0.0001$. Data were received from Statistics Sweden. [25] 
Inclusion criteria were being resident in the municipality for at least 5 years and also being supplied by the same water source for at least 5 years. Exclusion criteria were clinical conditions known to influence the metabolism of magnesium, such as acute myocardial infarction during the last 6 months, resection of the intestine, kidney failure, thyroid dysfunction with pharmacology treatment, use of diuretics, failure of the liver or abuse of alcohol.

In total, 105 men and women in Tocksfors and 102 in Osthammar matched the inclusion and exclusion criteria and participated in the study.

The individuals were invited to the local primary care centre for a physical examination. Each person delivered a tap water sample from his or her household on the day of the visit to the primary care centre.

Height and weight were measured in centimetres and kilograms and body mass index, (BMI) $\mathrm{kg} / \mathrm{m}^{2}$ was calculated. Blood pressure was measured in recumbent position after 5 minutes rest. Urine was collected during 24 hours in bottles prepared and delivered by the laboratory. The individuals were instructed and informed about the sampling by the nurse.

Blood samples were taken and a questionnaire was filled out by the participants and monitored by the study nurse. The questionnaire contained questions about social situation, medical history of cardiovascular disease, liver or kidney disorder, thyroid dysfunction and diabetes. Smoking and alcohol habits were also recorded.

Muscle biopsy in striated muscle (m. vastus) was conducted in 67 subjects, 29 in the western and 38 in the eastern municipality. Each individual in the study was asked to give his or her consent for the biopsy and all in this sample agreed.

Assessment of the dietary intake was made by a food frequency questionnaire based on an earlier questionnaire developed at the Department of Environmental Medicine, Göteborgs University.

The questionnaire was specifically aimed at quantitatively assessing magnesium and calcium in the diet, regarding portion sizes and use of local tap water in drinks and in food preparation. The use of mineral salt (Seltin) was also assessed.

There were twenty-two questions about the consumption of milk and milk products, fish, meat, bread and cereals, fruit, vegetables, nuts and snacks and four questions on the use of beer, wine, mineral water and tap water based drinks (coffee, tea, fruit juice etc).
The Department of Clinical Nutrition evaluated of the individual intake of magnesium and calcium. Individual basal metabolic rate (BMR) was calculated according to Schoefield et al. based on sex, age, weight and height [26]. In this population, the daily total energy expenditure was estimated to be $1.5^{*}$ BMR. This figure was used as an indication of the portion size (small, normal or large) for main meals in the individual calculations. For other types of food, household measures such as bottle, spoon, cup, slices etc., and standard portion size according to Swedish standards were used [27].

Data for calcium and magnesium content in foods were taken from food tables in "Swedish Food Data base" from the National Food Administration [28] and from manufacturers analyses of mineral water and from actual tap water analyses. For food ingredients such as rice, rolled oats, legumes (peas, beans, lentils) and, pasta, the calculations were made on dry weight, adding an appropriate amount of tap water or milk, for the preparation. The estimation of dietary calcium and magnesium, derived from local tap water was based on water analyses and the individual amount of water used, including food preparation and drinks.

\section{Laboratory methods}

Blood was drawn after an overnight fast, with no alcohol the last 24 hours and no smoking the last 3 hours, by venipuncture and in Vacutainer Tubes. Analyses were made at the Laboratory of Clinical Chemistry, Central Hospital in Karlstad. Calcium and magnesium content in whole blood, serum, muscle and urine was determined by atomic absorption spectrophotometry. Glycosylated haemoglobin, HbA1c, was determined by the ion exchange HPLC method. Water samples were taken in supplied bottles from the laboratory on the morning of the visit to the health centre and analysed for magnesium and calcium. The results were given in $\mathrm{mg} / \mathrm{l}$.

\section{Statistics}

The statistical package SPSS 10.1 was used for statistical analyses.

Differences between groups regarding continuous variables were analysed using Student's T-test and, for variables judged as skewed, the Mann-Whitney U-test. Regarding categorical variables the chi-squared test was used. Correlations were calculated using Spearman's rank-correlation coefficient.

Multivariate linear regression was performed to evaluate the relative importance of factors possibly contributing to the variation in risk factor levels. A stepwise procedure was used, whereby factors not significantly contributing 
Table 2: Descriptive socio-economic data.

\begin{tabular}{|c|c|c|c|}
\hline & West $N=105$ & East $\mathrm{N}=102$ & $\mathrm{P}$-value \\
\hline Age years* & $43.1(6.1)$ & $43.4(6.4)$ & .693 \\
\hline $\operatorname{Sex}(M / F)^{* *}$ & $47 / 58$ & $49 / 53$ & .636 \\
\hline Years living in the municipality* & $35.4(17.4)$ & $28.2(16.4)$ & .002 \\
\hline Years using same water supply* & $19.3(11.9)$ & $21.0(12.3)$ & .318 \\
\hline Educational level\%** & & & .004 \\
\hline Grammar school & 44 & 42.7 & \\
\hline Upper secondary school & 41 & 24.0 & \\
\hline University degree & 15 & 33.3 & \\
\hline
\end{tabular}

* Mean (sd), Student's T-test ** Chi-square test

Table 3: Health variables.

\begin{tabular}{llll}
\hline & West $\mathrm{N}=105$ & East $\mathrm{N}=102$ & P-value \\
\hline BMI $\left(\mathrm{kg} / \mathrm{m}^{2}\right)^{*}$ & $25.4(3.3)$ & $25.6(3.9)$ & .632 \\
Treated hypertension\%*** & 11.5 & 10.8 & .883 \\
$\mathrm{SBP} \mathrm{mm} \mathrm{Hg} * *$ & $124.7(\mathrm{I7.7})$ & $131.0(15.6)$ & .001 \\
DBP mm Hg** & $80.6(13.3)$ & $78.7(9.1)$ & .242 \\
Diabetes\% *** & 5.7 & 5.9 & .959 \\
Current smokers\%*** & 22.1 & 35.6 & .043 \\
Use of snuff\% *** & 12.3 & 8.3 & .406 \\
\hline
\end{tabular}

* Mean (sd). Student's T-test ** Median (range). Mann-Whitney U-test $* * *$ Chi-square test

Table 4: Laboratory variables.

\begin{tabular}{|c|c|c|c|}
\hline & West $N=105$ & East $\mathrm{N}=102$ & $\mathrm{p}$-value \\
\hline $\mathrm{S}-\mathrm{Ca} \mathrm{mmol} / \mathrm{I}^{*}$ & $2.33(0.08)$ & $2.32(0.06)$ & .357 \\
\hline S-GT $\mu \mathrm{mol} / \mathrm{I}^{* *}$ & $0.29(2.23)$ & $0.30(2.15)$ & .955 \\
\hline S-cholesterol mmol//* & $6.04(0.96)$ & $5.60(1.18)$ & .003 \\
\hline $\mathrm{S}-\mathrm{TG} \mathrm{mmol} / \mathrm{I}^{* *}$ & $1.10(6.00)$ & $1.15(10.10)$ & .536 \\
\hline $\mathrm{S}-\mathrm{HDL} \mathrm{mmol} / \mathrm{I}^{* *}$ & $1.30(1.6)$ & $1.30(2.0)$ & .582 \\
\hline $\mathrm{S}-\mathrm{LDL} \mathrm{mmol} / /^{* * *}$ & $4.15(4.00)$ & $3.29(4.99)$ & .0001 \\
\hline LDL/HDL* & $3.24(1.13)$ & $2.76(1.32)$ & .006 \\
\hline $\mathrm{S}-\mathrm{Mg} \mathrm{mmol} / /^{*}$ & $0.86(0.05)$ & $0.86(0.05)$ & .856 \\
\hline B-HbAlc\%* & $4.43(0.32)$ & $4.53(0.47)$ & .065 \\
\hline Whole blood magnesium mmol//* & $1.44(0.13)$ & $1.45(0.13)$ & .799 \\
\hline Magnesium in striated muscle $\mathrm{mmol} / \mathrm{I}^{*}$ & $6.60(1.72)(n=29)$ & $6.73(2.25)(n=38)$ & .807 \\
\hline Calcium in $24 \mathrm{hrs}$ urine $\mathrm{mmol} / /^{*}$ & $5.18(2.52)$ & $5.30(2.66)$ & .708 \\
\hline Magnesium in $24 \mathrm{hrs}$ urine $\mathrm{mmol} / \mathrm{l}^{*}$ & $4.18(1.54)$ & $4.25(1.74)$ & .697 \\
\hline Creatinine in $24 \mathrm{hrs}$ urine $\mathrm{mmol} / /^{*}$ & $11.18(3.93)$ & $12.25(4.93)$ & .087 \\
\hline
\end{tabular}

* Mean (sd), Student's T-test ** Median (range), Mann-Whitney U-test S- = serum, B- = blood

were excluded. Residuals were checked for normality and showed no disturbing features.

Internal dropout rate did not exceed $1 \%$ for any of the items.
P-values less than .05 were regarded as significant

\section{Results}

Table 2 shows descriptive socio-economic data. Age and gender were similar in the groups. The individual educational level was higher in the eastern municipality. The 
individuals in the west had been residents in the municipality more years than in the east.

Table 3 shows health variables of the participants. The prevalence of previous cardiovascular disorders, hypertension, BMI and diabetes did not differ between the groups, nor did the use of medication. Systolic blood pressure was higher, and smoking more common in the east than in the west.

Laboratory variables are presented in table 4 . The mean scholesterol was significantly higher in the west, as was the level of s-LDL-cholesterol and LDL/HDL. Water supplied by the municipality was used by $24.5 \%$ in the eastern municipality and $61.5 \%$ in the western, the rest using private wells.

The total hardness of water, defined as the sum of calcium and magnesium, in household water in the two municipalities is presented in Figure 1.

The median content of calcium in the household water was $12.5 \mathrm{mg} / \mathrm{l}$ in the west and 58 in the east with minimum and maximum values of 4.5-76.0 and 0.5-128.0 respectively. The median content of magnesium in the household water was $3.3 \mathrm{mg} / \mathrm{l}$ in the west and 5.4 in the east with minimum and maximum values of $0.7-14.3$ and $0.1-13.5$ respectively. The water from the major water supplies in the municipality in the east had a higher degree of hardness but the ratio $\mathrm{Mg} / \mathrm{Ca}$ being similar in the two areas, 0.06 in the east and 0.08 in the west. In the household water however, the $\mathrm{Mg} / \mathrm{Ca}$ ratio was 0.18 in the west and 0.09 in the east, which is statistically significant $\mathrm{p}=.0001$.

The use of water filter was $3.8 \%$ in the west and $10.8 \%$ in the east.

Of the individuals using water in the lowest quartile of water hardness were $92.3 \%$ living in the western municipality and $96.1 \%$ using water in the highest quartile were living in the eastern municipality. Dietary intake variables for the individuals in the two municipalities are presented in table 5 and 6 .

The median intake of calcium from diet did not differ significantly between groups living in the eastern and western municipalities. There were however, great interindividual differences. Overall, household water accounted for small amounts of the daily calcium and magnesium intake in both municipalities.

Milk and cheese were the main sources of calcium in the diet (around 60\%). In both areas the most important sources of calcium besides milk products were bread and

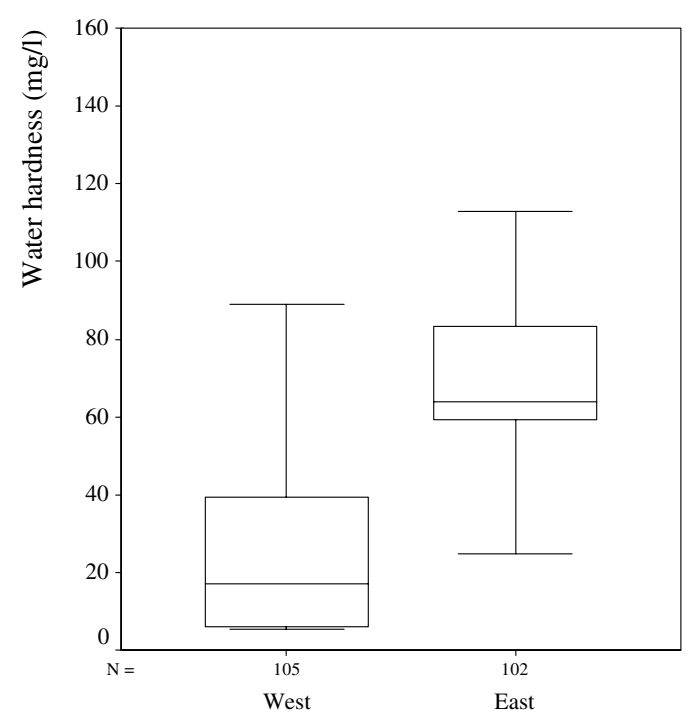

Figure I

Water hardness, defined as the sum of calcium and magnesium $(\mathrm{mg} / \mathrm{l})$, in household water delivered by the study participants in the western and eastern municipality.

cereals $(6-7 \%)$, followed by chocolate $(5 \%)$ and vegetables and fruit in the western area and by local water (4\%) and vegetables (3\%) in the east.

Magnesium intake from diet was higher in the west $(\mathrm{p}=$ 0.028 ). Important sources for magnesium were bread and cereals as well as milk products, each contributing about $25 \%$ of the magnesium intake in both areas. Potatoes (6$7 \%$ ), meat and fish (5-7\%), vegetables, fruit and berries $(5 \%)$ also supplied small amounts of magnesium. Overall, the participants in the western areas tended to consume more milk and chocolate and less beer/ wine than in the eastern areas.

In Table 7 correlations between calcium and magnesium in water and cardiovascular risk factors are presented in the total study population and for men and women. There were positive correlations between calcium in water and systolic blood pressure (SBP), and negative correlation for s-cholesterol and s-LDL-cholesterol. These correlations were also found for women, while for men only a correlation to SBP was found.

The same results were found for total water hardness defined as the sum of calcium and magnesium. 
Table 5: Dietary intake of calcium, mg/day, median (min-max).

\begin{tabular}{lll}
\hline & West $\mathrm{N}=105$ & East $\mathrm{N}=102$ \\
\hline $\begin{array}{l}\text { Ca, mg/day, total intake* } \\
\text { Source }\end{array}$ & $1023(184-4365)$ & $961(155-4613)$ \\
Local water & $10(0-126)$ & $45.2(0-297)$ \\
Milk \& cheese & $700(0-2573)$ & $610(21-4306)$ \\
Mineral water & $15(0-171)$ & $11(0-129)$ \\
Vegetables & $25(4-123)$ & $27(0-128)$ \\
Potatoes & $5(0-40)$ & $3(0-40)$ \\
Bread, cereals & $81(7-246)$ & $67(10-221)$ \\
Chocolate & $57(0-2857)$ & $13(0-1142)$ \\
Fruit, berries & $25(0-119)$ & $17(0-128)$ \\
Wine, beer & $2(0-38)$ & $11(0-54)$ \\
Meat, fish & $12(0-53)$ & $14(3-41)$
\end{tabular}

* Median (min-max). Mann-Whitney U-test. $\mathrm{P}=.228$

Table 6: Dietary intake of magnesium, mg/day, median (min-max).

\begin{tabular}{lll}
\hline & West $\mathrm{N}=105$ & East $\mathrm{N}=102$ \\
\hline $\begin{array}{l}\text { Mg, mg/day, total intake* } \\
\text { Source }\end{array}$ & $250(67-725)$ & $221(74-703)$ \\
$\quad$ Local water & $2.5(0-34)$ & $3.8(0-24)$ \\
Milk \& cheese & $61.7(0-263)$ & $54.7(1-460)$ \\
Mineral water & $3.0(0-33)$ & $2.0(0-21)$ \\
Vegetables & $13.3(2-68)$ & $12.8(0-49)$ \\
Potatoes & $16(0-140)$ & $16(0-140)$ \\
Bread, cereals & $70.4(7-258)$ & $68.8(8-221)$ \\
Chocolate & $8.6(0-429)$ & $2.8(0-186)$ \\
Fruit, berries & $11.4(0-74)$ & $11.5(0-51)$ \\
Wine, beer & $1.0(0-23)$ & $4.0(0-39)$ \\
Meat, fish & $14.0(0-40)$ & $17.9(3-64)$ \\
\hline
\end{tabular}

*Median (min-max). Mann-Whitney U-test $\mathrm{P}=.028$

There were no correlations between the ratio urine calcium/urine magnesium and SBP or DBP.

No correlations were found between magnesium in water and cardiovascular risk factors in the total population, although, for women there was a positive correlation to scalcium and a negative one to magnesium in muscle. For men there was a positive correlation to magnesium in muscle.

No significant correlations between calcium in diet and the risk factors were found. For magnesium in diet there was a positive correlation to DBP.

Correlations between content of calcium and magnesium in serum, urine and muscle with cardiovascular risk factors are shown in table 8 . For s-calcium there were positive correlations to s-cholesterol, s-triglycerides, s-LDL, SBP, $\mathrm{DBP}$, and $\mathrm{HbA1c}$. For s-magnesium there were positive correlations to s-TG and DBP and a negative correlation to s-HDL.

In regression analyses controlling for age and sex $18.5 \%$ of the variation in SBP was explained by the variation in BMI, HbA1c and calcium content in water. Some $27.9 \%$ of the variation in s-cholesterol could be explained by the variation in s-TG, and calcium content in water.

\section{Discussion}

In this study we used individual data to evaluate the role of water and diet magnesium and calcium on major cardiovascular risk factors, s-cholesterol, s-TG, s-LDL, and SBP and DBP. Since water compositions vary substantially even within small geographic areas using data from 
Table 7: Correlations between $\mathrm{Ca}$ and $\mathrm{Mg}$ in water and cardiovascular risk factors, calcium in serum and urine, and magnesium in serum, muscle and urine. Total study population and men and women. Spearman's rank correlation coefficient.

\begin{tabular}{|c|c|c|c|c|c|c|}
\hline & \multicolumn{3}{|c|}{ Calcium content in water } & \multicolumn{3}{|c|}{ Magnesium content in water } \\
\hline & $\begin{array}{l}\text { Total study } \\
\text { population }\end{array}$ & Women & Men & $\begin{array}{l}\text { Total study } \\
\text { population }\end{array}$ & Women & Men \\
\hline S-Cholesterol &.$-|7| *$ & $-.217 *$ & -.128 & -.070 & -.158 & .002 \\
\hline S-TG & .056 & .198 & .002 & .101 & .150 & .070 \\
\hline S- HDL-cholesterol & .005 & -.022 & .003 & -.093 & -.062 & -.112 \\
\hline S-LDL-cholesterol & $-.218^{* *}$ & $-.282^{*}$ & -.169 & -.087 & -.175 & -.024 \\
\hline SBP & $.229^{* *}$ & $-274^{*}$ & $.195^{*}$ & .128 & .169 & .091 \\
\hline DBP & .032 & .122 & -.020 & .028 & .066 & -.005 \\
\hline B- $\mathrm{HbAlc}$ & .043 & -.015 & .088 & .064 & .015 & .106 \\
\hline $\mathrm{S}-\mathrm{Ca}$ & -.011 & -.148 &.$-|5|$ & .073 & $.232 *$ & -.057 \\
\hline S-Mg & .009 & .055 & .004 & .014 & .081 & -.037 \\
\hline $\mathrm{U}-\mathrm{Ca}$ & .002 & .016 & -.012 & -.075 & -.014 & -.133 \\
\hline U-Mg & .021 & .094 & -.029 & -.038 & .063 & -.109 \\
\hline M-Mg & -.095 & -.146 & -.017 & -.007 & $-.412^{*}$ & $.394^{*}$ \\
\hline
\end{tabular}

** Correlation is significant at the $.0 \mathrm{I}$ level $*$ Correlation is significant at the .05 level $\mathrm{S}-=$ serum, $\mathrm{B}-=$ blood, $\mathrm{U}_{-}=$urine. $\mathrm{M}-=$ muscle

Table 8: Correlations between calcium and magnesium in serum, muscle and urine and major cardiovascular risk factors. Spearman's rank correlation coefficient.

\begin{tabular}{|c|c|c|c|c|c|c|c|c|c|c|c|c|}
\hline & $\mathrm{S}-\mathrm{Ca}$ & U-Ca & $\mathrm{S}-\mathrm{Mg}$ & U-Mg & M-Mg & S-cholesterol & S-TG & S-HDL & S-LDL & SBP & DBP & $\mathrm{HbAlc}$ \\
\hline $\mathrm{S}-\mathrm{Ca}$ & 1.000 & .022 & $.268^{* *}$ & -.018 & .052 & $.285^{* *}$ & $.260 * *$ & -.074 & $.245^{* *}$ & $.227^{* *}$ & $.242 * *$ & $.207^{* *}$ \\
\hline U-Ca & & 1.000 & -.009 & $.586 * *$ & -.029 & -.047 & .075 & -.123 & -.015 & $.174^{*}$ & .140 & .130 \\
\hline S-Mg & & & 1.000 & -.071 & .111 & .082 & $.204^{* * *}$ & $-.202 * *$ & .092 & .077 & $.174^{*}$ & .064 \\
\hline $\mathrm{U}-\mathrm{Mg}$ & & & & 1.000 & .178 & -.068 & .010 & -.102 & -.019 & $.186 * *$ & $.201^{* *}$ & $.202^{* *}$ \\
\hline $\mathrm{M}-\mathrm{Mg}$ & & & & & 1.000 & .002 & .010 & .004 & .031 & -.010 & .054 & $.255^{*}$ \\
\hline $\begin{array}{l}\text { S-Cho- } \\
\text { lesterol }\end{array}$ & & & & & & 1.000 & $.426 * *$ & -.119 & $.950 * *$ & .042 & .140 & $.266 * *$ \\
\hline S-TG & & & & & & & 1.000 & $-.614 * *$ & $.379 * *$ & $.236 * *$ & $.246 * *$ & .123 \\
\hline S- HDL & & & & & & & & 1.000 & $-.286^{*}$ & $-.174 *$ & $-.212^{* *}$ & $-.150 *$ \\
\hline S-LDL & & & & & & & & & 1.000 & .042 & $.183 * *$ & $.280 * *$ \\
\hline SBP & & & & & & & & & & 1.000 & $.646 * *$ & $.278 * *$ \\
\hline DBP & & & & & & & & & & & 1.000 & $.213 * *$ \\
\hline B- & & & & & & & & & & & & 1.000 \\
\hline $\mathrm{HbAlc}$ & & & & & & & & & & & & \\
\hline
\end{tabular}

* Correlation is significant at the .05 level $* *$ Correlation is significant at the .01 level $\mathrm{S}-=$ serum, $\mathrm{B}-=$ blood, $\mathrm{U}_{-}=$urine. $\mathrm{M}-=$ muscle

municipality water supplies could give an incorrect risk estimate. We therefore used the composition of water from the actual use of household water. We found, however, that even if $92.3 \%$ and $96.1 \%$ respectively of the individuals living in soft and hard water areas were using household water in the lowest and highest quartile of water hardness there were great variations within the geographic area.

Since magnesium has been considered the water factor most likely to have an influence on cardiovascular mortal- ity attention in the study was focused on magnesium as well as water hardness and calcium.

We have used the available methods for analysing magnesium and calcium; in serum, whole blood, and urine. Since there is only a weak correlation between the magnesium content of different body compartments, it remains unclear which method best reflects body magnesium [29]. This fact makes it hard to evaluate the role of s-magnesium as the marker of magnesium status of the body. 
The content of magnesium in drinking water in various countries was found to range between 0 and $111 \mathrm{mg} / \mathrm{l}$ according to previous studies [1-12]. The magnesium content in the water of Sweden is lower than in most other countries due to geological circumstances. This could explain why magnesium in our study is not shown to be the water factor.

The mean daily intake of calcium, $1023 \mathrm{mg}$ to $961 \mathrm{mg}$ in the west and east respectively, was close to the average dietary calcium supply in Sweden of $1100 \mathrm{mg}$ (1995-1999) [30]. Unfortunately, there are no statistical data from Sweden regarding magnesium supply, the recommended daily intake being $350 \mathrm{mg}$ for men and $280 \mathrm{mg}$ for women. The average daily intake in the UK is $323 \mathrm{mg}$ for men and $237 \mathrm{mg}$ for women [31]. In our present study the daily intake were $250 \mathrm{mg}$ in the west and $221 \mathrm{mg}$ in the east. There were large variations within the groups as regards the consumption of various foods, and consequently also large variations in the intake of minerals. Milk consumption varied from nothing to more than 2 litres a day; most persons not drinking milk had a high intake of cheese, but - in fact about $50 \%$ of both men and women got less calcium and magnesium than recommended [32].

The negative correlations we found between calcium in water and s-cholesterol and s-LDL indicated that a high content of calcium could lower the levels of s-cholesterol and s-LDL but on the other hand increase SBP. The individuals living in the east had higher SBP. The absence of correlations between calcium and magnesium in water to calcium and magnesium in serum should be noted. The lack of correlation between magnesium content in water and risk factors is unclear and needs further research.

There was a significant correlation between s-magnesium and s-calcium, which is an expected normal condition in healthy subjects.

S-calcium showed several positive correlations to cardiovascular risk factors: s-cholesterol, s-TG, s-LDL, SBP, DBP, and $\mathrm{HbA} 1 \mathrm{c}$ and s-magnesium had positive correlations to s-TG and DBP, and a negative correlation to s-HDL. This indicates that high s-calcium and s-magnesium increases the levels of metabolic factors that are considered to elevate the risk for cardiovascular disease.

The regression analyses of the variation in s-cholesterol, and SBP demonstrate the complexity of interactions between major risk factors where calcium in water could be a factor of importance.

Since a major part of the magnesium and calcium intake is known to be dietary, this study included diet recordings on an individual basis. The food frequency questionnaire used was designed to capture the calcium and magnesium in the diet.

When considering hard water as a protective factor for cardiovascular disease, the importance of locally produced food has also been discussed. A study has been performed to evaluate the changes in the mineral composition of food as a result of cooking in hard and soft water [33]. The results show that magnesium is extracted from food by cooking, most pronounced in soft water. The calcium content increased in food when cooked in hard water and decreased in soft water. In the present study, the mineral content in foods like pasta and beans was supposed to have increased, e.g. $50 \mathrm{~g}$ of pasta plus $100 \mathrm{~g}$ of water corresponds to $150 \mathrm{~g}$ of cooked pasta including the minerals in local water. Otherwise, most of the local water was consumed as drinks.

\section{Conclusion}

This study of individuals living in soft and hard water areas showed significant correlations between the content of calcium in water and major cardiovascular risk factors. This was not found for magnesium in water or calcium or magnesium in diet. Regression analyses indicated that calcium content in water could be a factor in the complexity of relationships and importance of cardiovascular risk factors. From these results it is not possible to conclude any definite causal relation and further research is needed.

\section{Competing interests}

None declared.

\section{Authors' contributions}

$\mathrm{CN}$ carried out the planning of the study and has been the principal investigator and drafted and coordinated the writing of the manuscript. LA carried out the clinical work at one of the centres and participated in writing the manuscript. RAL was responsible for the diet recording and analysing the results concerning diet and contributed in writing of the manuscript. PN performed the statistical analysis and contributed to the writing of the manuscript. KS participated in the study design and contributed to the writing of the manuscript.

All authors read and approved the final manuscript.

\section{Acknowledgements}

This study as supported by grants from the County Council of Värmland, The Swedish Medical Association, and the Heart Lung Foundation.

Dr Lennart Nordstrom for the laboratory analyses. Dr Marie Lindgren and nurses and staff at the participating Primary Care centres in Tocksfors and Osthammar.

John Lindgren, Arvika, for performing the laboratory analysis of water. 
Ann-Charlotte Nilsson for excellent secretarial assistance.

\section{References}

I. Nerbrand C, Svardsudd K, Ek J and Tibblin G: Cardiovascular mortality and morbidity in seven counties in Sweden in relation to water hardness and geological settings. The project: myocardial infarction in mid-Sweden Eur Heart J 1992, 13:72 1-7.

2. Comstock GW: Water hardness and cardiovascular diseases Am J Epidemiol 1979, I | 0:375-400.

3. Pocock SJ, Shaper AG, Cook DG, Packham RF, Lacey RF, Powell P and PF Russell: British Regional Heart Study: geographic variations in cardiovascular mortality, and the role of water quality $\mathrm{Br}$ Med J 1980, 280: I243-9.

4. Masironi R, Pisa $Z$ and Clayton D: Myocardial infarction and water hardness in the WHO myocardial infarction registry network Bull World Health Organ 1979, 57:291-9.

5. Karppanen $\mathrm{H}$ : Epidemiological studies on the relationship between magnesium intake and cardiovascular diseases Artery 1981, 9:190-9.

6. Luoma H, Aromaa A, Helminen S, Murtomaa H, Kiviluoto L, Punsar S and Knekt P: Risk of myocardial infarction in Finnish men in relation to fluoride, magnesium and calcium concentration in drinking water Acta Med Scand 1983, 2 I 3: I7 I-6.

7. Leary WP, Reyes AJ, Lockett CJ, Arbuckle DD and van der Byl K: Magnesium and deaths ascribed to ischaemic heart disease in South Africa. A preliminary report S Afr Med J 1983, 64:7756.

8. Marx A and Neutra RR: Magnesium in drinking water and ischemic heart disease Epidemiol Rev 1997, 19:258-72.

9. Rubenowitz $\mathrm{E}$, Axelsson $\mathrm{G}$ and Rylander R: Magnesium in drinking water and death from acute myocardial infarction $A m ~ J$ Epidemiol 1996, 143:456-62.

10. Rubenowitz E, Axelsson G and Rylander R: Magnesium and calcium in drinking water and death from acute myocardial infarction in women Epidemiology 1999, 10:31-6.

II. Reunanen A, Knekt P, Marniemi J, Maki J, Maatela J and Aromaa A: Serum calcium, magnesium, copper and zinc and risk of cardiovascular death Eur J Clin Nutr 1996, 50:431-7.

12. Maheswaran R, Morris S, Falconer S, Grossinho A, Perry I, Wakefield $\mathrm{J}$ and Elliott $\mathrm{P}$ : Magnesium in drinking water supplies and mortality from acute myocardial infarction in north west England Heart 1999, 82:455-60.

13. Kesteloot $\mathrm{H}$ : Blood pressure, calcium and water-hardness In: Handbook of hypertension 1985.

14. Sauvant MP and Pepin D: Drinking water and cardiovascular disease Food Chem Toxicol 2002, 40:1311-25.

15. Kesteloot $\mathrm{H}$ and Joossens JV: Relationship of dietary sodium, potassium, calcium, and magnesium with blood pressure. Belgian Interuniversity Research on Nutrition and Health Hypertension 1988, I 2:594-9.

16. Joffres MR, Reed DM and Yano K: Relationship of magnesium intake and other dietary factors to blood pressure: the Honolulu heart study Am J Clin Nutr 1987, 45:469-75.

17. Dyckner $T$ and Wester PO: Effect of magnesium on blood pressure Br Med J (Clin Res Ed) 1983, 286: I847-9.

18. Anderson TW, Neri LC, Schreiber GB, Talbot FD and Zdrojewski A: Letter: Ischemic heart disease, water hardness and myocardial magnesium Can Med Assoc J 1975, I I 3: 199-203.

19. Elwood PC, Sweetnam PM, Beasley WH, Jones D and France R: Magnesium and calcium in the myocardium: cause of death and area differences Lancet 1980, 2:720-2.

20. Chipperfield B, Chipperfield JR, Behr G and Burton P: Magnesium and potassium content of normal heart muscle in areas of hard and soft water Lancet 1976, I:121-2.

21. Chipperfield B and Chipperfield JR: Differences in metal content of the heart muscle in death from ischemic heart disease $A m$ Heart J 1978, 95:732-7.

22. Landin: Skeletal muscle magnesium and drinking water magnesium level Magnesium Bull I989.

23. Galan P, Arnaud MJ, Czernichow S, Delabroise AM, Preziosi P, Bertrais S, Franchisseur C, Maurel M, Favier A and Hercberg S: Contribution of mineral waters to dietary calcium and magnesium intake in a French adult population J Am Diet Assoc 2002, I02: 1658-62.

24. Community water register 1995.

25. Statistics Sweden, Stockholm 2000.
26. Schofield WN: Predicting basal metabolic rate, new standards and review of previous work Hum Nutr Clin Nutr 1985, 39 Suppl I:5-4l.

27. Weight tables. national Food Administration 1999.

28. Swedish Food Administration. Food composition table. Energy and nutrients. Liber tryck AB, Stockholm 1997.

29. Dyckner T and Wester PO: Magnesium deficiency - guidelines for diagnosis and substitution therapy Acta Med Scand Suppl |982, 66 1:37-41.

30. Swedish Board of Agriculture, Statistics 2000.

31. Gregory: The dietary and nutritional survey of British adults. London HMSO 1990.

32. The Nordic Nutrient Recommendations Stockholm 1996.

33. Haring BS and Van Delft W: Changes in the mineral composition of food as a result of cooking in "hard" and "soft" waters Arch Environ Health 1981, 36:33-5.

\section{Pre-publication history}

The pre-publication history for this paper can be accessed here:

http://www.biomedcentral.com/1471-2458/3/21/prepub
Publish with Bio Med Central and every scientist can read your work free of charge

"BioMed Central will be the most significant development for disseminating the results of biomedical research in our lifetime. "

Sir Paul Nurse, Cancer Research UK

Your research papers will be:

- available free of charge to the entire biomedical community

- peer reviewed and published immediately upon acceptance

- cited in PubMed and archived on PubMed Central

- yours - you keep the copyright

Submit your manuscript here:

http://www.biomedcentral.com/info/publishing_adv.asp
BioMedcentral 